\title{
The Influence of Microencapsulated Phase Change Material (PCM) Characteristics on the Microstructure and Strength of Cementitious Composites: Experiments and Finite Element Simulations
}

\author{
Matthew Aguayo ${ }^{*}$, Sumanta Das ${ }^{\dagger}$, Amit Maroli $^{\ddagger}$, Nihat Kabay ${ }^{\S}$, James C.E Mertens ${ }^{* *}$, \\ Subramaniam D. Rajan $^{\dagger+}$, Gaurav Sant ${ }^{\ddagger \ddagger}$, Nikhilesh Chawla ${ }^{\S \S}$, Narayanan Neithalath ${ }^{* * *}$
}

\begin{abstract}
Phase Change Materials (PCMs) incorporated into cementitious systems have been well-studied with respect to energy efficiency of building envelopes. New applications of PCMs in infrastructural concrete, e.g., for mitigating early-age cracking and freeze-and-thaw induced damage, have been proposed. Hence this paper develops a detailed understanding of the characteristics of cementitious systems containing two different microencapsulated PCMs. The PCMs are evaluated using thermal analysis, vibrational (FTIR) spectroscopy, and electron microscopy, and their dispersion in cement pastes is quantified using X-ray Computed Microtomography $(\mu \mathrm{CT})$. The influences of PCMs on cement hydration and pore structure are evaluated. The compressive strength of mortars containing PCMs is noted to be strongly dependent on the encapsulation properties. Finite element simulations carried out on cementitious microstructures are used to assess the influence of interface properties and inter-inclusion interactions. The outcomes provide insights on methods to tailor the component phase properties and PCM volume fraction so as to achieve desirable performance.
\end{abstract}

Keywords: Phase Change Materials (PCMs), Microstructure, Dispersion, Pore Structure, Compressive Strength, Finite Element Analysis

\footnotetext{
${ }^{*}$ Graduate student, School of Sustainable Engineering and the Built Environment, Arizona State University, Tempe AZ

${ }^{+}$Graduate student, School of Sustainable Engineering and the Built Environment, Arizona State University, Tempe AZ

${ }^{\ddagger}$ Graduate student, School of Sustainable Engineering and the Built Environment, Arizona State University, Tempe AZ

$\S$ Post-doctoral researcher, School of Sustainable Engineering and the Built Environment, Arizona State University, Tempe AZ

** Graduate student, Materials Science and Engineering, Arizona State University, Tempe AZ

${ }^{+\dagger}$ Professor, School of Sustainable Engineering and the Built Environment, Arizona State University, Tempe AZ

${ }^{\ddagger}$ Assistant Professor, Department of Civil and Environmental Engineering, University of California Los Angeles, Los Angeles, CA; Member, California Nanosystems Institute

$\S \S$ Professor, Materials Science and Engineering, Arizona State University, Tempe AZ

Associate Professor, School of Sustainable Engineering and the Built Environment, Arizona State University, Tempe AZ, Corresponding Author; Narayanan.Neithalath@asu.edu; Phone: 001-480-965-6023; Fax: 001-480-965-0557
} 


\subsection{INTRODUCTION}

Among the multitude of methods to enhance the energy efficiency of building materials and indoor thermal comfort, one method that has gained prominence is the use of thermal energy storage (TES) materials. Phase change materials (PCMs) are combined sensible-and-latent thermal energy storage materials that can be used to store and dissipate energy in the form of heat [1-5]. A large number of recent studies have focused on the use of PCMs in building materials to achieve this objective [6-10]. Several methods have been advanced to incorporate PCMs in concrete, including direct incorporation and in the form of microencapsulated particles [11-13]. Microencapsulated PCMs, that are commercially available in a powder form, can be directly added during the mixing process of concrete [14-18]. The other common approach is to employ macro encapsulation, which refers to the impregnation of PCMs as a liquid into the pores of lightweight aggregates, which are then used as inclusions in concrete [19-21].

A recent work has outlined the other advantages that PCMs can offer to structural concretes by virtue of their capacity to store and release heat [18]. The influence of microencapsulated PCMs on semiadiabatic temperature rise and cool-down rates in hydrating cementitious systems, the development of restrained thermal stresses and strains that result in thermal cracking, and on the fracture properties have been elucidated in the aforementioned study. PCMs having suitable phase change enthalpy and phase transition temperatures can also: (i) restrict the magnitude of diurnal-or-seasonal temperature variations and deformations of restrained concrete elements over long time scales to limit damage due to thermal fatigue, and (ii) help limit the number and/or intensity of freeze-thaw cycles experienced by exposed concrete structures $[20,22]$.

The applications described above require concretes to demonstrate adequate thermo-physical and mechanical properties over extended time periods. In general, incorporation of soft inclusions such as PCMs (either in the micro- or macro-encapuslated forms) decreases the mechanical properties of the composite including its strength and stiffness $[17,18]$. The property reductions are substantial in the case of cement pastes; however the presence of stiffer phases such as aggregates can reduce the severity of property loss. It is also possible to mitigate some of the property loss through appropriate material design including matrix strengthening methods [18,23]. Previous studies also have noted degradation of microcapsules in cementitious systems $[17,23]$. The ability to store and release heat also depends on the pore volume, sizes, and their distribution in the cementitious system, which could be impacted by the incorporation of PCMs [24], as well as the size and dispersion of PCM particles. All of 
these necessitate a fundamental characterization of the PCMs and their effects on cementitious systems in order to design: (i) mechanical performance-equivalent systems containing adequate amounts of PCMs as needed to satisfy thermal requirements, and/or (ii) microencapsulated PCMs capable of enduring mechanical and chemical stresses produced during mixing and placing concrete, and induced due to the high $\mathrm{pH}$ cementitious environment.

This paper examines the influence of two microencapsulated PCMs having different particle sizes, and that are encapsulated in shells that have different physico-chemical and mechanical properties, on the microstructure and properties of the resultant cementitious system. A fundamental characterization of the microencapsulated PCMs is carried out, as are studies on microstructure and mechanical response of the resulting composites. Relevant insights on the influence of the PCM encapsulation and geometry on the resulting properties, and pointers to appropriate material design of PCM-cement composites are obtained through a combination of advanced experimental tools and finite element simulations.

\subsection{EXPERIMENTAL PROGRAM}

\subsection{Materials and Mixtures}

A commercially available Type I/II ordinary portland cement (OPC) conforming to ASTM C150, and two different microencapsulated, paraffinic phase change materials (PCMs) referred to as PCM-M and PCME were used. The median particle size $\left(d_{50}\right)$ of OPC is $10 \mu \mathrm{m}$ and that for PCM-E is $7 \mu \mathrm{m}$ as determined by laser diffraction. The median particle size of PCM-M was determined as $10 \mu \mathrm{m}$ by laser diffraction; however this is the size of the primary particles in the agglomerations of PCM-M. PCM-M comprises of agglomerations 20 -to-300 $\mu \mathrm{m}$ in size, which are composed of many small particles in the 5-10 $\mu \mathrm{m}$ range (see Figure 1), which break down during dispersion prior to particle size analysis. More details are presented in Section 3.1.

Nine mortars and their corresponding pastes were proportioned with a volumetric water-to-powder ratio, $(w / p)_{v}=1.26$ (mass-based $\left.w / p \approx 0.40\right)$, which are shown in Table 1 . The mortar samples were proportioned with a constant paste volume of $50 \%$. In addition to the control OPC mortar/paste, the mixtures included PCM at four volumetric inclusion levels of 5, 10, 15, and 20\% of both PCM-M and PCM-E. For the mechanical property tests, PCM was used as a partial replacement of the fine aggregates (sand) in the mortar. The mortar specimens were stored in a moist chamber $\left(>97 \% \mathrm{RH}, 23 \pm 2^{\circ} \mathrm{C}\right)$ until the desired age of testing. Compressive strengths were determined at 1, 3, 7, and 28 days, and flexural strengths at 28 days of hydration. The paste samples were stored in sealed conditions at room temperature until being tested at 28 days of hydration. 
Table 1: Mixture proportions for $1 \mathrm{~m}^{3}$ of mortar or paste

\begin{tabular}{ccccccc}
\hline \multirow{2}{*}{ Mixture } & \multicolumn{2}{c}{ Cement $(\mathrm{kg})$} & \multicolumn{2}{c}{ PCM $(\mathrm{kg})$} & \multicolumn{2}{c}{ Quartz Sand $(\mathrm{kg})$} \\
\cline { 2 - 7 } & Mortar & Paste & Mortar & Paste & Mortar & Paste \\
\hline OPC & 650 & 1070 & 0 & 0 & 1119 & 0 \\
PCM-5\% & 667 & 1063 & 6 & 10 & 1091 & 0 \\
PCM-10\% & 684 & 1056 & 12 & 21 & 1060 & 0 \\
PCM-15\% & 702 & 1048 & 19 & 33 & 1027 & 0 \\
PCM-20\% & 721 & 1037 & 26 & 46 & 993 & 0 \\
\hline
\end{tabular}

\subsection{Experimental Methods}

\subsubsection{Scanning electron microscopy and infrared spectroscopy}

The microstructure of the PCMs and the pastes incorporating PCMs was visualized using Field Emission Environmental scanning electron microscope (FESEM, Philips XL30). The pastes were crushed and small pieces from the core were impregnated with an epoxy resin and sectioned to facilitate imaging in secondary electron mode. Fourier Transform Infrared (FTIR) Spectroscopy was performed to identify the functional groups and compounds in the two different PCMs used in this study. This was accomplished using a Mattson Genesis spectroscope fitted with an attenuated total reflection (ATR) attachment containing a diamond head, which enabled the samples to be examined directly without further preparation. The region of interest in the FTIR spectra of the PCMs was $3500-700 \mathrm{~cm}^{-1}$.

\subsubsection{X-ray tomography}

Cement paste samples containing $10 \%$ PCM by volume of the paste were analyzed in an X-ray computed microtomography $(\mu \mathrm{CT})$ system. The paste samples were machined into cylindrical samples $1.5 \mathrm{~mm}$-to-2 $\mathrm{mm}$ in diameter and $5 \mathrm{~mm}$ high. A lab-scale $\mu \mathrm{CT}$ system designed and built at the 4D Materials Science Laboratory at ASU was used [25-27]. The test was performed with a transmission tungsten target microfocus X-ray source. Projections were acquired with the $\mathrm{x}$-ray tube operating at an accelerating voltage of $80 \mathrm{kV}$ and a target power of $6 \mathrm{~W}$. A $0.025 \mathrm{~mm}$ steel filter was applied between the $\mathrm{x}$-ray source and the sample to improve the $\mathrm{x}$-ray beam quality. The X-ray detector consisted of a CCD camera optically coupled with a $4.185 x$ lens to a $250 \mu \mathrm{m}$ thick LuAG:Ce scintillator. X-ray projections were acquired $\left(2048 \times 2048\right.$ pixels, $(15 \mu \mathrm{m})^{2}$ square pixels) using a pixel binning factor of two, resulting in projections in $1024 \times 1024$ format. Scanning was conducted by acquiring $x$-ray projections at $0.25^{\circ}$ rotational increments over a scan range of $210^{\circ}$ with $30 \mathrm{~s}$ exposure per orientation resulting in $38 \mathrm{k}$ background counts. The distance from the X-ray target to the scintillator during scanning was 
maintained at $42.4 \mathrm{~mm}$. The total system magnification (the product of the X-ray magnification and the lens magnification) in conjunction with the CCD pixel size and the acquisition binning parameter resulted in a voxel size of approximately $1.53^{3} \mu^{3}$ for the PCM-E sample and $1.80^{3}{\mu m^{3}}^{3}$ for the PCM-M sample in the volume reconstructions.

The volume reconstructions were performed using a MATLAB filtered back projection implementation of the cone-beam, FDK algorithm, with the Shepp-Logan filter applied, resulting in a $1024^{3}$ voxel volume $[26,27]$. The raw reconstructions were processed for noise reduction to enable particle segmentation. Filtering and segmentation were performed using Avizo Fire ${ }^{\mathrm{TM}}$. First, the symmetric nearest neighbor (SNN) filter was applied in 3D using a kernel size of $3^{3}$. Second, a Gaussian blurring operation was applied in all three orthogonal directions. Finally, an adaptive 2D Non-Local Means filter was applied in the reconstruction planes. This filtering process was established by trial and error to yield $\mu \mathrm{CT}$ data which was most conducive to particle segmentation.

\subsubsection{Pore structure}

The porosity and the critical pore diameter of the PCM modified pastes were determined using mercury intrusion porosimetry (MIP) at 28 days of hydration. Samples were pre-treated in an oven at $60^{\circ} \mathrm{C}$ for 2 hours. This methodology has been shown to provide consistent results for cementitious samples [28]. The porosimeter was capable of evaluating a minimum pore diameter of $0.003 \mu \mathrm{m}$ and applied a maximum pressure of $414 \mathrm{MPa}$. The contact angle and surface tension values used were $117^{\circ}$ and 0.485 $\mathrm{N} / \mathrm{m}$ respectively, as these values are reported in the literature to be typical for oven dried samples $[29,30]$. The pore diameters were evaluated using the Washburn equation, based on the assumption that the pores are cylindrical in shape.

\subsubsection{Thermal analysis}

The thermal properties (e.g. onset and peak temperatures, enthalpy) of the microencapsulated PCMs were determined using a differential scanning calorimeter. The thermal program used for analysis included a temperature sweep where the sample was heated from $-20^{\circ} \mathrm{C}$ to $60^{\circ} \mathrm{C}$ followed by a ramp down cooling to $-20^{\circ} \mathrm{C}$ in an inert nitrogen environment. A rate of temperature change (i.e., heating and cooling) of $5^{\circ} \mathrm{C} / \mathrm{min}$ was used.

Simultaneous thermal analysis (STA) was performed on the microencapsulated PCMs and on hardened cement pastes. The tests were performed in an inert $\mathrm{N}_{2}$ environment. The samples were heated from ambient temperature to $800^{\circ} \mathrm{C}$ at a heating rate of $15^{\circ} \mathrm{C} / \mathrm{min}$. 


\subsubsection{Compressive and flexural strength determination}

The compressive strengths of $50 \mathrm{~mm}$ mortar cubes were determined as per ASTM C 109 at a given specimen age. The flexural strengths were measured using standard center-point loading as per ASTM C 293/293M-10 on rectangular beams (305 mm (span) x 76 mm (depth) x 25 mm (width)).

\subsection{RESULTS AND DISCUSSIONS}

\subsection{Characterization of the Microencapsulated PCMs}

This section presents a comprehensive characterization of the microstructural, chemical, and thermal characteristics of the two PCMs used in this study. The micrographs in Figure 1 depict the morphology of the PCMs used in this study (PCM-M and PCM-E). It is apparent that PCM-M (Figures 1(a)-(c)) shows an agglomerated structure composed of many individual PCM microcapsules. PCM-E (Figure 1(d)), on the other hand, shows many individual PCM microcapsules that are distinct and present no agglomeration. Agglomeration in PCM-M can be attributed to the manufacturing process and the degree of cross-linking of the polymer used to synthesize the shell covering the PCMs [31-34]. The extent of cross linking also determines the mechanical properties of the polymer shell $[35,36]$, which influences the properties of the composite containing PCMs, as will be shown later in this paper.
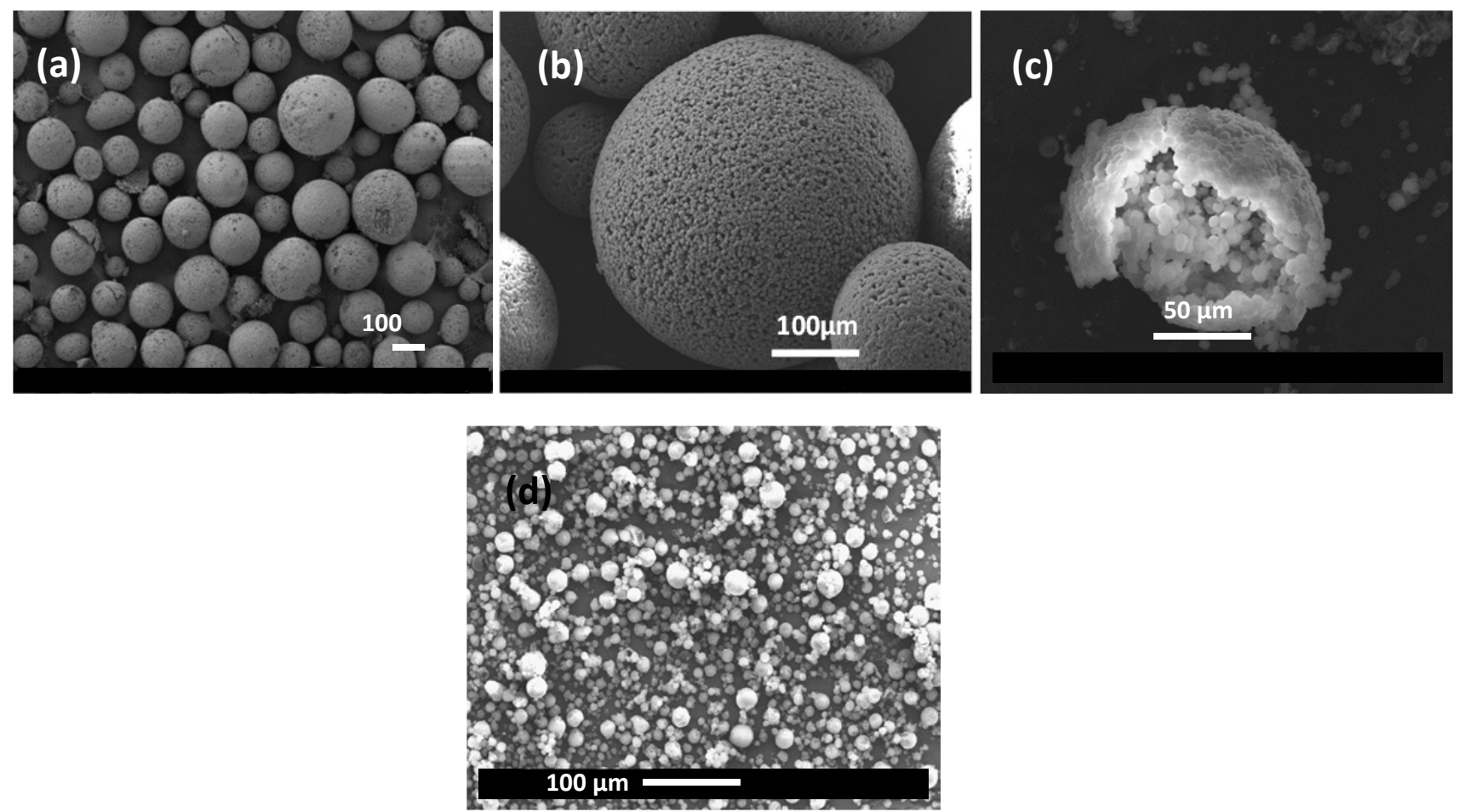
Figure 1: Micrographs of: (a) PCM-M, (b) and (c) PCM-M showing smaller capsules that are agglomerated to form the larger capsule, and (d) PCM-E, which is composed of discrete particles.

Thermogravimetric traces of both the PCMs are shown in Figure 2. Both the PCMs decompose almost completely by about $500^{\circ} \mathrm{C}$. The derivative (DTG) curve shows two distinct peaks: a first (dominant) peak associated with the decomposition of the paraffin that is encapsulated within the shell, and a second peak associated with the decomposition of the polymer encapsulation [37]. For PCM-M the thermal degradation of the paraffin occurs in the temperature range of 175 to $275^{\circ} \mathrm{C}$ whereas the paraffin in PCM-E decomposes in the temperature range of 200 to $350^{\circ} \mathrm{C}$; most likely a result of their differing molecular weights. This is also manifested in their thermal properties (enthalpy and phase transition temperature). The second peak corresponding to the decomposition of the polymeric shell occurs in the 280 to $400^{\circ} \mathrm{C}$ range for $\mathrm{PCM}-\mathrm{M}$, which is similar to that reported in $[33,38]$ for polymethylmethacrylate (PMMA) encapsulated paraffins. For PCM-E, the decomposition temperature of the shell is in the range of 320 to $450^{\circ} \mathrm{C}$, which corresponds to melamine formaldehyde (MF) which has a decomposition temperature around $300-450^{\circ} \mathrm{C}[39,40]$. It has been reported that a higher degree of cross-linking in the polymeric microcapsule results in its thermal degradation shifting to higher temperatures [40]. MF shells are shown to have a compact cross-linked structure and the encapsulations are defect-free spheres [41] as seen in Figure 1. Table 2 shows the mass loss associated with the paraffin, polymeric capsule, and the left over residue. The mass content of the capsule material is higher for PCM-M, which can be attributed to its structure where many small capsules agglomerate to form a larger capsule. PCM-E has a much larger core-to-shell ratio than PCM-M. The polymeric shell of PCM-E, though smaller in quantity, exhibits an increased thermal resistance than that of PCM-M (as observed from the higher decomposition temperature for the shell material in Figure 2), which can be attributed to higher cross linking in MF. A larger core content is generally likely to result in poor formation of the shell walls and thus decreases the stability of the microcapsules [42]. However, the results in the subsequent sections in this paper suggest that for PCM-E, this problem has been overcome, possibly through chemical modification of MF $[40,43]$.
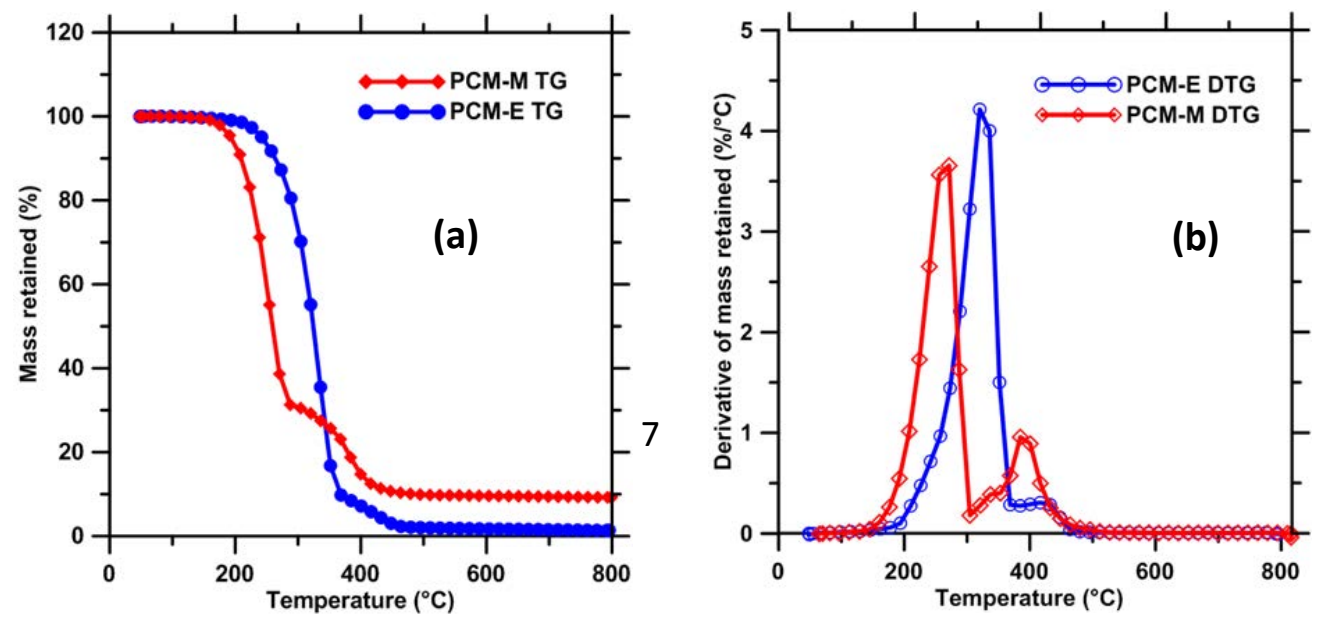
Figure 2: (a) Thermogravimetric (TG), and (b) differential TG curves of PCM-M and PCM-E.

Fourier Transform Infrared (FTIR) spectra of both the PCMs are shown in Figure 3(a). The spectral peaks in the $2950 \mathrm{~cm}^{-1}$ to $2850 \mathrm{~cm}^{-1}$ range are attributed to the aliphatic C-H stretching vibration, the peak at $1465 \mathrm{~cm}^{-1}$ is attributed to $\mathrm{C}-\mathrm{H}$ bending, and the peak at $717 \mathrm{~cm}^{-1}$ corresponds to the in-plane rocking vibration of the $\mathrm{CH}_{2}$ group. These spectral vibration peaks are related to the paraffins in the PCM-M and PCM-E. The other spectral peaks at $1730 \mathrm{~cm}^{-1}$ and the multiple peaks from $1250 \mathrm{~cm}^{-1}$ to $1000 \mathrm{~cm}^{-1}$ correspond to the carbonyl group of the co-polymer and C-O stretching of the co-polymer respectively. The FTIR spectra shown in Figure 3 are similar to those reported for other microencapsulated PCMs $[33,37,43]$. The intensity of the peak at $1730 \mathrm{~cm}^{-1}$ corresponding to the carbonyl group is much higher for PCM-E as observed in Figure 3(a), which represents a stronger bond between the associated carbonyl groups. It has been reported that a stronger intensity of the peak at $1730 \mathrm{~cm}^{-1}$ is an indication of the stability of the polymeric shell structure [44]. Thus, even with a lower shell content, the polymeric capsule of PCM-E is likely more structurally stable than that of PCM-M, which indicates its encapsulation efficiency.

Table 2: Chemical composition PCM-M and PCM-E as extracted from TG data

\begin{tabular}{|c|c|c|c|c|}
\hline \multirow{2}{*}{\begin{tabular}{c} 
Chemical Composition \\
\cline { 2 - 5 }
\end{tabular}} & $\begin{array}{c}\text { Amount } \\
(\%)\end{array}$ & $\begin{array}{c}\text { Decomposition } \\
\text { temp. range }\left({ }^{\circ} \mathrm{C}\right)\end{array}$ & Amount (\%) & $\begin{array}{c}\text { Decomposition } \\
\text { temp. range }\left({ }^{\circ} \mathrm{C}\right)\end{array}$ \\
\hline Paraffin wax & 69.50 & $100-300$ & 90.22 & $100-370$ \\
\hline Polymeric capsule & 20.70 & $300-510$ & 7.67 & $370-480$ \\
\hline Residue & 9.80 & $510-800$ & 2.10 & $480-800$ \\
\hline Core-to-shell ratio (mass-based) & \multicolumn{3}{|c|}{3.4} & \multicolumn{2}{|c|}{11.8} \\
\hline
\end{tabular}

Figure 3(b) shows representative DSC curves of the microencapsulated PCMs (PCM-M and PCM-E). DSC scans were carried out in the temperature range of $-10^{\circ} \mathrm{C}$ to $50^{\circ} \mathrm{C}$ at a heating rate of $5^{\circ} \mathrm{C} / \mathrm{min}$. The enthalpy of phase change of the PCMs was determined as the area under the main heat flow curve during the phase transition. The enthalpies of phase change of the PCMs used in this study were found to be 100 and $159 \mathrm{~J} / \mathrm{g}$ respectively for PCM-M and PCM-E. This is in agreement with published results for 
similar PCM types $[33,38]$. For PCM-M, the onset temperature ( $\left.\mathrm{T}_{\text {onset }}\right)$ corresponding to melting is $21.1^{\circ} \mathrm{C}$ and the completion temperature $\left(T_{\text {completion }}\right)$ is $26.0^{\circ} \mathrm{C}$, with the endothermic peak $\left(T_{\text {peak }}\right)$ noted at $24.3^{\circ} \mathrm{C}$. The onset, offset and peak temperatures for PCM-E was $19.5,25.0$ and $23.4^{\circ} \mathrm{C}$ respectively.
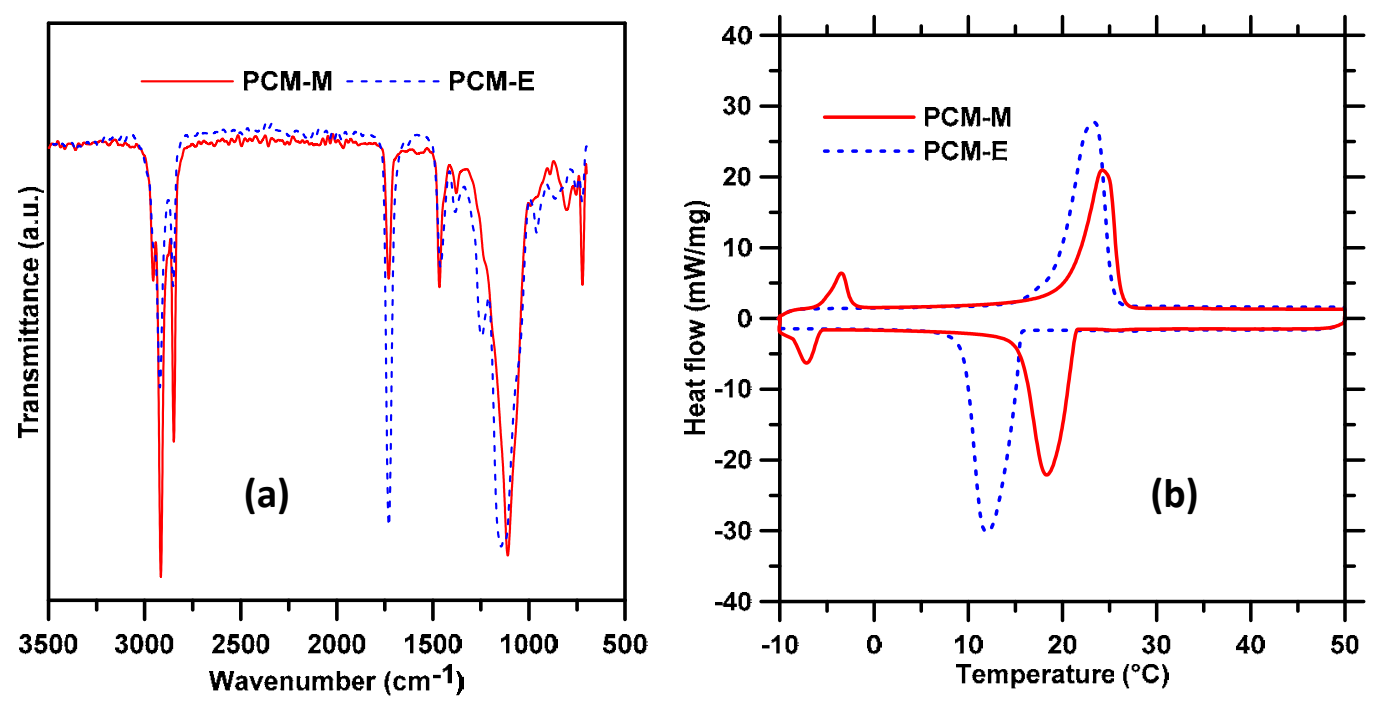

Figure 3: (a) FTIR spectra, and (b) DSC scans, of PCM-M and PCM-E.

\section{2 $\mu \mathrm{CT}$ Studies on the Dispersion of PCMs in Cement Pastes}

The dispersion characteristics of PCM-M and PCM-E in hardened cement paste are presented here through the use of $\mu \mathrm{CT}$. CT provides valuable 3D information on the morphology and structure of random heterogeneous materials, which is generally unavailable otherwise. Both these systems were designed to contain $10 \%$ of PCM by volume. Cubic volumes of interest of sizes ranging from $600^{3} \mu^{3}$ to $900^{3}{\mu \mathrm{m}^{3}}^{3}$ were extracted from different areas of the original 3D reconstructions, in order to determine the influence of the size of the representative volume element (RVE) on the accuracy of the extracted volume fraction and dispersion parameters of the PCMs. A transition point-based thresholding approach $[45,46]$ (in the grey scale histogram), where a small increment in the threshold values causes a sharp change in the detected phase quantities, is employed to effectively segment PCM phases in the cement paste. The greyscale value (represented in a scale of 0-255) for pores was in the range of 0-12, while for the PCM micorcapsules, the range was 31-44. The transition point-based segmentation method therefore was sufficient to distinguish PCM particles from pores due to significant difference in absorption contrast between the two phases. Figures $4(\mathrm{a})$ and (b) show the distribution of PCM-M and 
PCM-E respectively in a cubic RVE of $900 \mu \mathrm{m}$ edge length, where the transition point-based segmentation algorithm has been implemented to separate the PCM phases from the cement paste. Figure 4(a) clearly shows large PCM-M capsules which are agglomerated. Careful examination also reveals locations where the larger capsules have disintegrated, i.e., the agglomerations are broken. On the contrary, a more uniform distribution of smaller particles of PCM-E in the cement paste is shown in Figure 4(b), which likely influences the mechanical behavior of these systems.

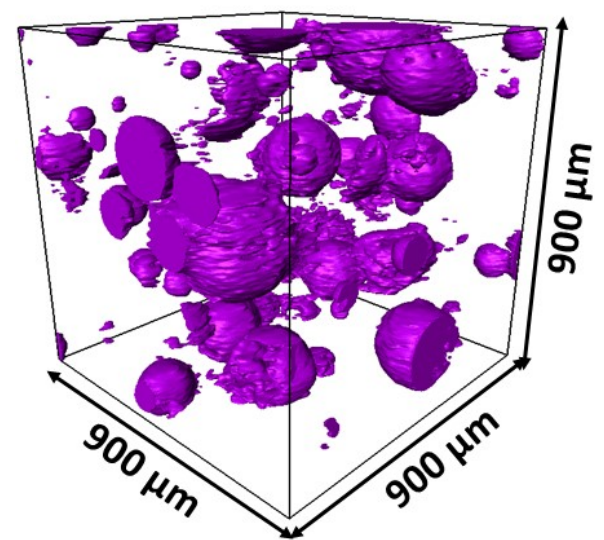

(a)

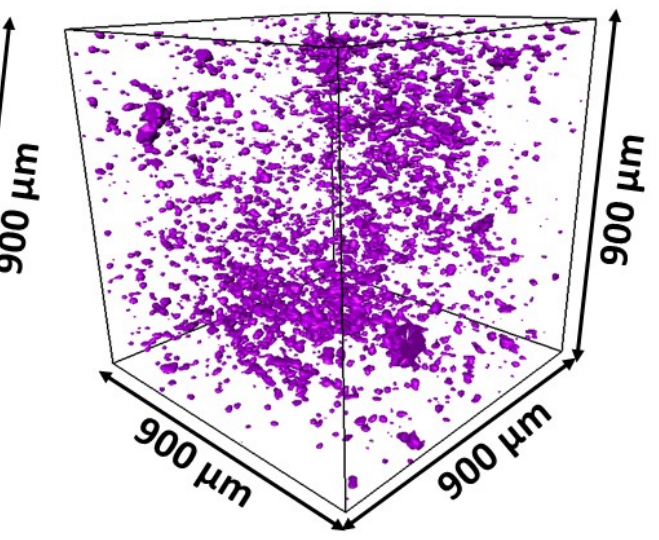

(b)

Figure 4: Representative cubical volumes of interest $\left(900^{3} \mu \mathrm{m}^{3} \mathrm{RVE}\right)$ extracted from the $\mu \mathrm{CT}$ dataset for: (a) PCM-M and (b) PCM-E.

Figure 5(a) depicts the influence of the RVE size on the segmented volume fraction of PCMs in both the systems while Figure $5(b)$ shows the differential particle size distribution of both the PCM types in cement pastes. A number of RVEs of different sizes were extracted from different regions of the original 3D $\mu C T$ image. The average segmented PCM volume fraction remains near invariant of the RVE size even though the variability is much larger as expected when smaller RVEs are used, as shown in Figure 5(a). The paste containing PCM-E shows a lower PCM volume fraction (about 8\%) than as-designed (10\%), which can be attributed to the image resolution of $1.8 \mu \mathrm{m}$; in other words particles smaller than this size are not detected. For PCM-M, the individual particle sizes are larger than the resolution limit and thus easily identified. The PCM volume fraction in the paste is overestimated at smaller RVEs when PCM-M is used. The differential size distribution in Figure 5(b) shows that there are PCM-M agglomerates as large as $300 \mu \mathrm{m}$ while the maximum size of the PCM-E particles is less than $50 \mu \mathrm{m}$. Thus for smaller RVEs, finite size error is an issue for pastes containing PCM-M. 
To quantify the dispersion of these two types of PCMs, the mean free spacing in 3D is determined based on stereological relationships obtained using the $2 \mathrm{D}$ slices from the $3 \mathrm{D} \mu \mathrm{CT}$ images. The mean free spacing is given as $[47,48]$ :

$$
d_{M F S}=\frac{\pi\left(1-\phi_{P C M}\right) \phi_{P C M}}{L_{A}}
$$

Here, $\phi_{\mathrm{PCM}}$ is area fraction of PCM obtained from planar images, and $\mathrm{L}_{\mathrm{A}}$ is the perimeter length of the PCMs per unit area of the image extracted from several 2D planar images obtained from 3D $\mu C T$. The area fraction and sizes of PCM particles are obtained using standard transition point based segmentation algorithm implemented in Avizo Fire $^{\mathrm{TM}}$ as explained earlier. The perimeter is then computed from the diameter of PCM particles. The mean free spacing of PCM-M in the cement paste is $60 \pm 8 \mu \mathrm{m}$ for an RVE of $0.9 \mathrm{~mm}$ edge length, while that of PCM-E is $12 \pm 1 \mu \mathrm{m}$, signifying the increased level of dispersion of PCM-E in the matrix. The $d_{90}$ for PCM-E is $25 \mu \mathrm{m}$ and that of PCM-M $130 \mu \mathrm{m}$ as
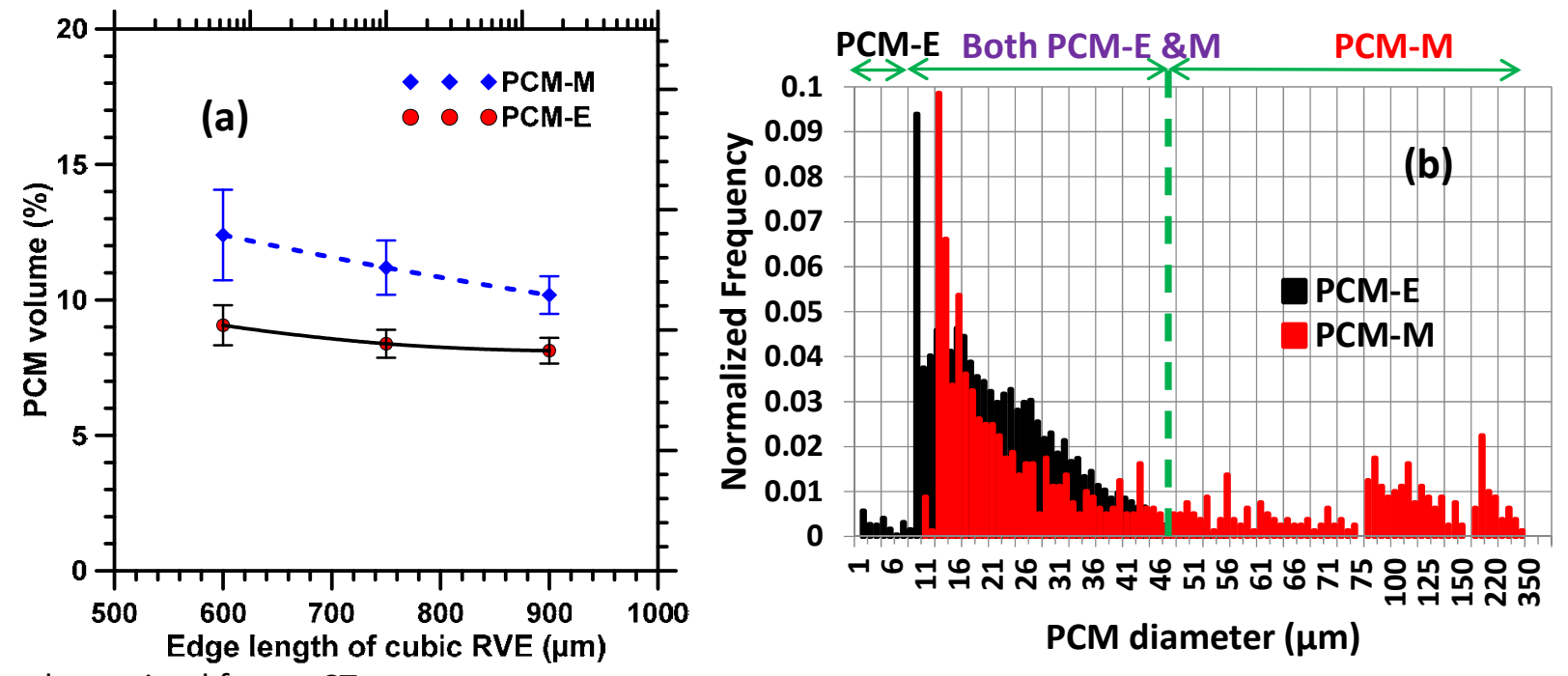

determined from $\mu \mathrm{CT}$.

Figure 5: (a) PCM volume fraction determined from $\mu C T$ as a function of the RVE size; (b) comparison of PCM size distribution frequency in a cubic RVE of $900 \mu \mathrm{m}$ edge length

\subsection{Microstructure and Pore Structure of Pastes Containing PCM}

The microstructures of cement pastes incorporating both the types of PCMs are shown in Figure 6. Figures $6(a-c)$ depict the microstructure of pastes containing PCM-M whereas Figures $6(d-f)$ show the same for PCM-E containing pastes. Figures 6(a) and (d) show how the microencapsulated particles are 
distributed in the cement paste matrix. Figure 6(b) shows that some of the individual nodules from the PCM-M particles separate when the PCMs are mixed into the cement paste, and the agglomerated capsule as seen in Figure 1 does not stay undamaged. The individual PCM-E particles are found to retain their shape in Figure 6(e) with a dense hydration product layer around the particle and a good particleto-paste bond. Figure 6(c) shows the formation of hydration products on the surface of the individual broken capsules of PCM-M, while Figure 6(f) shows a continuous layer of products on the PCM-E particle. While the PCM-E particles are seen to retain their shape and stability in the cement pastes, the PCM-M particles are more prone to damage as can be observed from Figure 6(c) that shows the deformed shape (indicative of rupture) of the individual microcapsules in the aggregation. It is also noticed that the interface between the shell and the paste is better when PCM-E is used. These micrographs provide an overview of the state of the microcapsules in the cement paste system which significantly influences the mechanical (and thermal) properties of the composite as will be detailed in the forthcoming section.
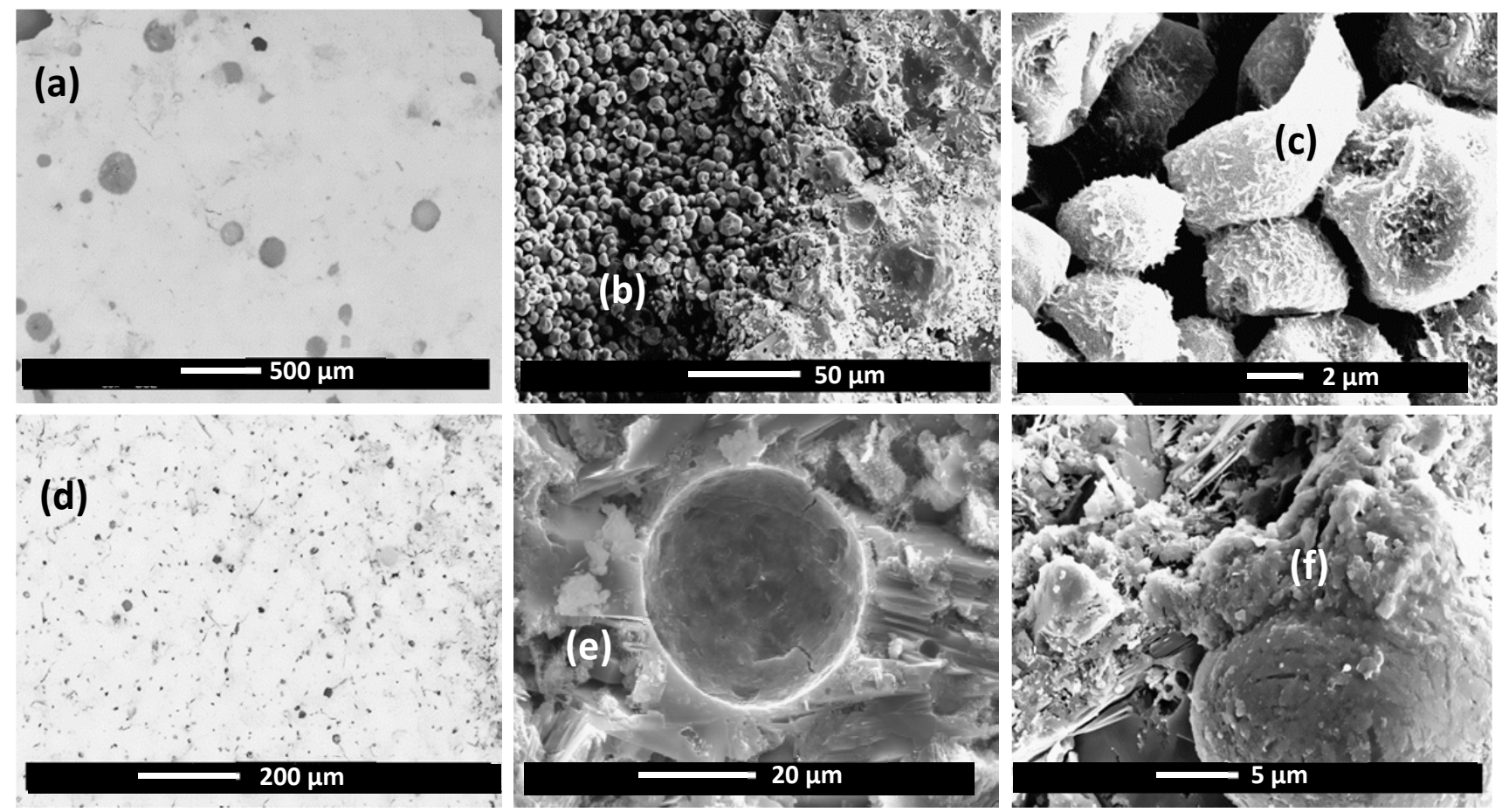

Figure 6: Microstructure of cement pastes incorporating PCMs: (a) PCM-M dispersed in cement paste, (b) breakage of PCM-M agglomerates into individual nodules in the cement paste, (c) cement hydration products on individual PCM-M nodules, (d) PCM-E dispersed in cement paste, (e) intact PCM-E microcapsule with hydration products around, and (f) dense reaction product around a PCM-E particle. 
The influence of PCMs on the cement hydration reactions and the amounts of hydration products formed was evaluated using thermogravimetric (TG) analysis. TG curves for the PCM-cement systems showed additional mass loss signatures corresponding to the decomposition of the PCM and its encapsulation as was shown in an earlier section. To evaluate the influence of PCMs on cement hydration, the calcium hydroxide $(\mathrm{CH})$ contents in these pastes, normalized by the mass of OPC in the paste, are reported in Figure 7(a) as a function of the PCM volume fraction. The cement pastes were hydrated for 28 days. Note that the plain and PCM modified pastes have the same water-to-cement ratios (by mass) since the PCM replaced the paste fraction and not the cement fraction. The $\mathrm{CH}$ contents were adjusted by accounting for the mass loss of the PCM capsule within this temperature range also since the decomposition temperature of the polymeric shell falls within the same range as the decomposition of $\mathrm{CH}$. For pastes containing both types of PCMs, the normalized $\mathrm{CH}$ content increases with PCM volume fraction, and the effect is more pronounced for the systems containing PCM-E. This indicates that the smaller PCM particles act as nucleation sites for the formation of $\mathrm{CH}$. Since the fraction of smaller particles are higher for PCM-E, the increase in normalized $\mathrm{CH}$ content is also pronounced for pastes containing this PCM. The micrographs shown in Figure 6 indicated the formation of reaction products around or on the PCM particles (or the separated individual nodules), which corroborates this observation.
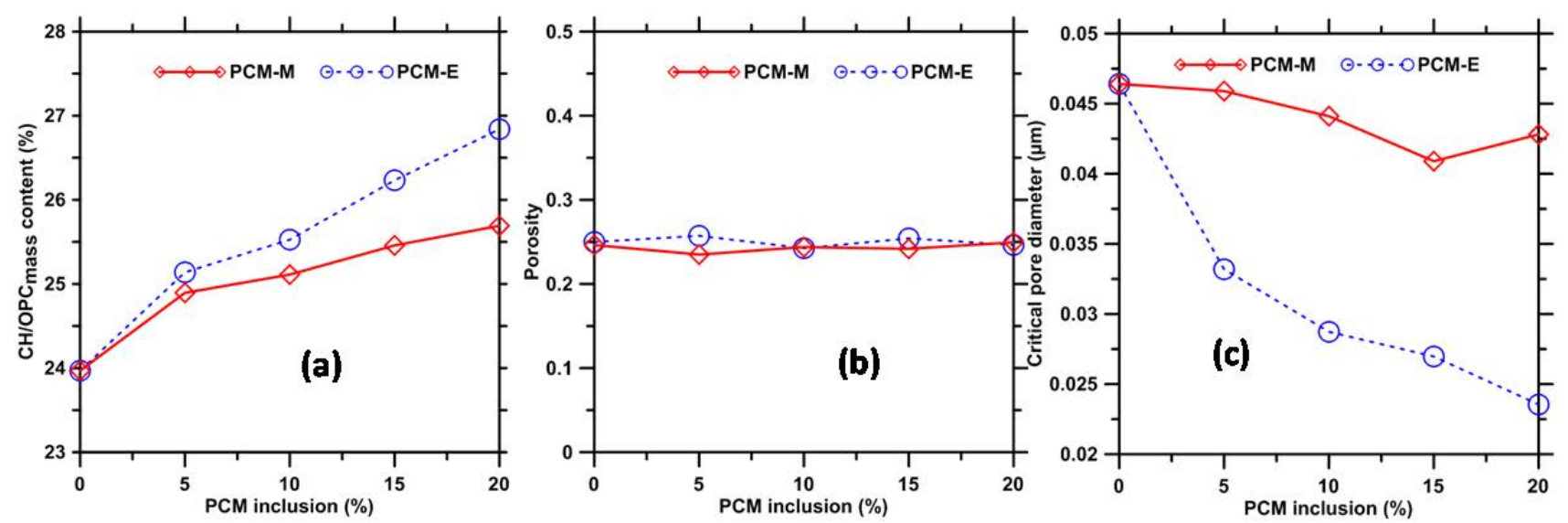

Figure 7: (a) Normalized CH content, (b) total porosity, and (c) critical pore size, as a function of PCM volume fraction for pastes containing PCM-M or PCM-E. The uncertainty in $\mathrm{CH}$ measurements is not more than $2 \%$, while those for porosity and critical pore size determinations range from $2 \%$ to $5 \%$.

Figures $7(b)$ and (c) show the total porosity and critical pore size respectively of the pastes containing both the PCMs. It is interesting to note that the porosity values as determined using MIP is invariant of the PCM dosage or the PCM type in these systems. The mixtures were proportioned using a constant 
water-to-cement ratio, and the PCMs were incorporated as a replacement of the paste; thus the porosity of the paste fraction remains unchanged. The actual volume of mercury intruded per unit mass of the paste increases with increasing PCM content, but the porosity remains relatively unchanged because of the reduction in effective density that accompanies PCM incorporation. Thus the overall volume of pores in the paste fraction that is measured by MIP is the same irrespective of the PCM type or dosage. However, observations of the critical pore diameter, which is an indication of percolating pore size and thus dictates the durability of the cementitious system, shows that there is a significant reduction in this parameter when PCM-E is added to the cement pastes. This is likely a result of enhanced reactivity where the smaller PCM-E particles provide nucleation sites, which result in an increased $\mathrm{CH}$ content.

\subsection{Compressive Strength of Mortars Containing PCM-M and PCM-E}

The compressive strength development as a function of age for mortars containing different volume fractions of PCM as replacement of the fine aggregate (sand) are shown in Figures 8(a) and (b) for mortars containing PCM-M and PCM-E respectively.
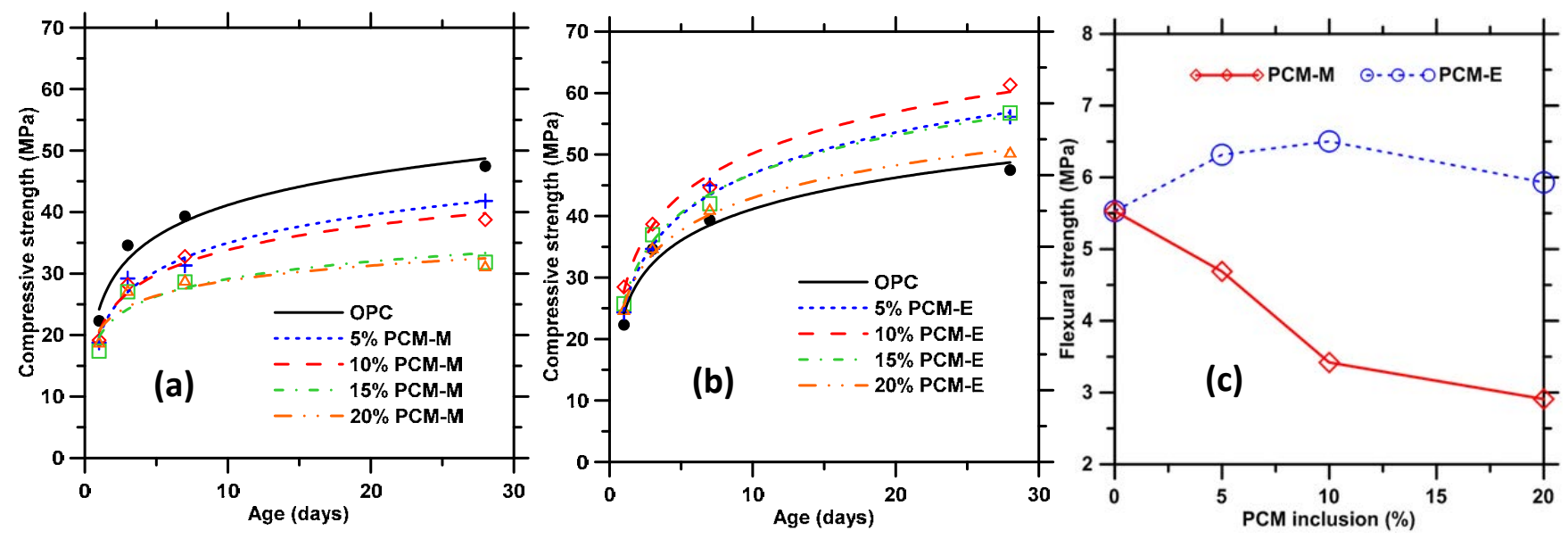

Figure 8: (a) and (b) Compressive strengths as a function of time for mortars containing different volume fractions of PCM-M (a), and PCM-E (b). The standard deviation in compressive strengths ranged between 2 and $5 \mathrm{MPa}$ early ages and 4 and $10 \mathrm{MPa}$ at later ages. (c) flexural strengths at 28 days as a function of PCM volume fraction. The standard deviation in flexural strengths were less than $0.8 \mathrm{MPa}$.

A significant difference is noted between the compressive strength trends of mortars containing PCM-M and PCM-E. While there is a consistent reduction in strength when PCM-M replaces sand in the mortars, the strengths of mortars containing up to $15 \%$ of PCM-E by volume are higher than that of the plain mortar at all ages. The strength, in the latter case, is highest when $10 \%$ by volume of PCM replaces sand, 
and then further decreases with increasing PCM content in the mortar - while still remaining higher than that of the plain mortar. Similar trends are noticed in flexural strengths, as shown in Figure 8(c). Previous studies have noted reductions in compressive strength of concrete when PCMs are added $[10,14]$. The decrease in strength was a proposed to be due to the addition of significant amounts of a material that offers no mechanical resistance, and/or the rupture of the nodules and the resultant release of the organic PCM into the cementitious matrix that detrimentally interferes with cement hydration. In the case of PCM-M incorporated in mortars, this explanation is consistent; see also Figure 6. The agglomerated PCM-M disintegrates in the mixing phase, creating numerous weak zones in the matrix, thereby providing the same effect that voids have on cementitious systems.

On the other hand, PCM-E particles are more uniformly dispersed, remain intact in the matrix and are coated by the cementitious reaction products (see Figure 6). The polymeric shell covering the active PCM core is also different for PCM-M and PCM-E as shown in Section 3.1. The properties of the shell, along with a denser interface in the system containing PCM-E, likely influences the stress sharing with the matrix, which results in differing responses for the systems containing PCM-M and PCM-E. While the compressive strengths of PCM-incorporated mortars showed diverging trends based on the PCM type, the strength of the paste mixtures were found to consistently reduce with increasing PCM volume fraction as has been observed elsewhere [18,23], irrespective of the PCM type (albeit a larger strength drop for pastes containing PCM-M as compared to those containing PCM-E). Thus it is also conceivable that the overall effects of matrix-inclusion (sand or PCM) interaction on the stresses in the volume of interest is influenced by the relative fractions of strong and hard quartz (sand) particles, and weak and soft PCM-E particles, and the mechanical properties of the interfacial region. As such, the forthcoming section investigates these effects using finite element simulations to better understand and explain the experimental observations on the strength of mortars containing PCM-E.

\subsection{Finite Element (FE) Simulations for the Strength of Mortars Containing PCM}

This section presents a microstructure-guided FE analysis of mortars in which a fraction of sand is replaced by PCM-E in an attempt to evaluate the matrix-inclusion interactions including the effects of interfaces on the compressive response of the mortar. An analysis of mortars containing PCM-M is not reported here since the agglomeration of nodules and their breakage render them analogous to voids as shown in Figure 8.

\subsubsection{Model parameters and material properties}


A two-dimensional plane strain finite element (FE) model is used to characterize and compute the compressive properties of the mortar as shown in Figure 9. Using symmetry boundary conditions, onequarter of the (square) model is used to include quartz particles and/or PCM inclusions arranged in a square lattice within a cement paste matrix. This is a simplified model; however as presented in the remainder of this section, this model helps understand the potential failure paths in systems containing heterogeneous inclusions as is the case of cement mortar containing PCMs. In mortars with higher inclusion volume fractions (such as $50 \%$ or greater) as considered here, it is very likely that the inclusions line up as shown in the model. The analysis is performed using ABAQUS ${ }^{T M}$. The top face of the geometry is subjected to uniform compressive loading parallel to the $\mathrm{Y}$-axis. The model considers an inclusion (mortar with 10\% PCM-E replacing quartz) volume of 50\%, consistent with the mortars used in the experiments. The edge length of the representative element area (REA) for all the mortar models is taken as $114 \mu \mathrm{m}$ to accommodate enough (36 in this case) quartz (sand) or PCM inclusions so as to capture inter-particle effects. The diameter of both the quartz and the PCM-E particles are taken as 15 $\mu \mathrm{m}$ for ease of analysis even though the median size of quartz particles is an order of magnitude larger than that of PCM-E. The size consideration is part of a detailed forthcoming study; however when the quartz size is increased to represent reality, the REA will have fewer large quartz particles and more PCM particles which are more dispersed in the REA. This will result in stress concentrations that are more dispersed in the matrix (as will be shown later), and thus the case that is considered here is a more conservative one. In addition, a weaker interfacial transition zone (ITZ) - a region of higher porosity exists around the hard quartz inclusions in mortars as has been well documented [49-52]. This reduces the mechanical properties at the quartz-paste interface, and to account for that, an interfacial layer is provided around the inclusions in the model (Figure 9). For the particle size considered in this model, the interface layer thickness is taken as $1 \mu \mathrm{m}$. If larger quartz particles are used to represent real cases, the weak interfacial zones around them will be thicker, leading to even larger stress concentrations. Thus, from this consideration too, the model shown here is conservative. For the case of PCM-E, micrographs shown in Figure 6 reveal a dense and likely stronger interface, which is accounted for in the model.

The elastic properties of the components in the mortars - cement paste, quartz aggregates, the core and shell of PCM-E, and the quartz-cement and PCM-E-cement interfaces - are presented in Table 3. These values are adopted from [53-57]. PCM-E contains a core encapsulated by a polymeric shell. The constitutive relationships for cement paste and quartz are considered to be linear elastic whereas the constitutive material model for PCM core and shell are adopted as bilinear elasto-plastic with strain 
hardening. The material properties for the core and shell of the PCM capsules are adopted from experimental data for similar systems reported in $[55,58]$.

Table 3 Elastic properties of the components of the mortars for the FE simulations

\begin{tabular}{|c|c|c|c|c|c|c|}
\hline Elastic property & $\begin{array}{c}\text { Hardened } \\
\text { cement } \\
\text { paste } \\
{[53,54]}\end{array}$ & $\begin{array}{c}\text { Quartz } \\
{[57]}\end{array}$ & $\begin{array}{c}\text { Cement } \\
\text { paste } \\
\text { interface } \\
{[53]}\end{array}$ & $\begin{array}{c}\text { Cement } \\
\text { paste } \\
\text { interface }\end{array}$ & $\begin{array}{c}\text { Core } \\
{[58]}\end{array}$ & $\begin{array}{c}\text { Shell } \\
{[55,56]}\end{array}$ \\
\hline Young's Modulus, E (GPa) & 20 & 70 & 16 & 24 & 0.0557 & 9 \\
\hline Poisson's Ratio, v (--) & 0.22 & 0.17 & 0.22 & 0.22 & 0.495 & 0.34 \\
\hline
\end{tabular}

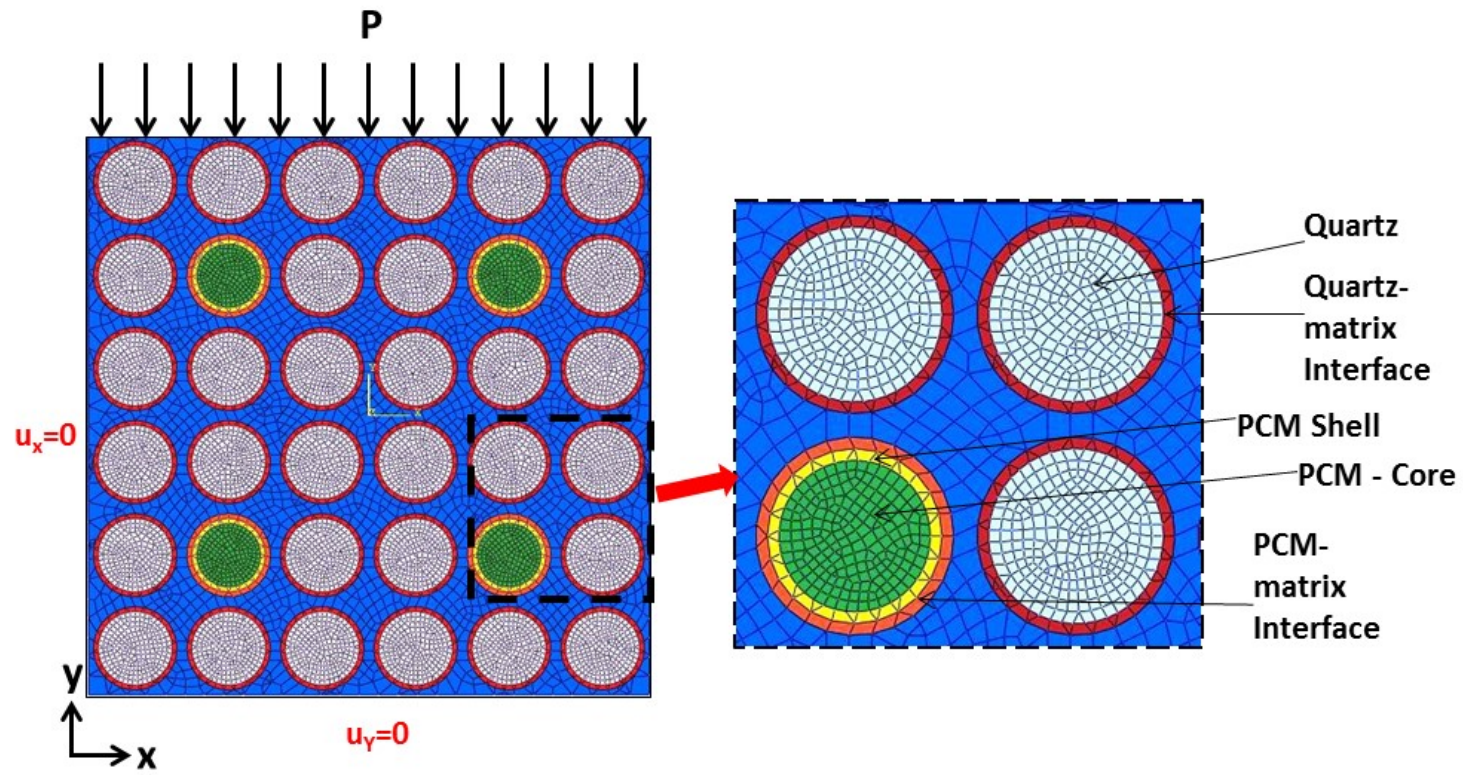

Figure 9: FE model showing the boundary conditions, applied compressive loading, and a magnified representation of the inclusions with the zones around them. The model contains $50 \%$ of inclusions (mortar with 10\% PCM-E particles replacing quartz particles) by volume (or area), consistent with the mortars used in the experiments.

Three different mortar models are implemented in this study: (i) the first with a quartz volume fraction of $50 \%$, (ii) the second where $\sim 10 \%$ of quartz is replaced by PCM-E, and (iii) the third where $50 \%$ of quartz is replaced by PCM-E. PCM-E consists of a paraffin core and a polymer (melamine formaldehyde Section 3.1) shell of $1 \mu \mathrm{m}$ thickness. The PCM-E shell is very strong in compression ( 250 MPa [59]). In addition, as mentioned earlier, a paste-inclusion interfacial layer of $1 \mu \mathrm{m}$ is also used. The meshing is done by seeding the edges of the different surfaces in the model individually in order to obtain nonuniform meshing for computational efficiency. The elements in the matrix are larger whereas the 
possible areas of stress concentration such as the interfacial elements, the PCM shell, and the core of the inclusions contain more refined meshes as can be seen in Figure 9. Free quad-dominated 4-noded bilinear plane strain quadrilateral elements (CPE4 element implemented in ABAQUS ${ }^{\mathrm{TM}}$ ) are used in the FE models. A mesh convergence study was carried out to establish that the required responses showed a converging trend. The finest mesh (10689 nodes and 11282 elements) that yielded a converged solution is shown in Figure 9 and is used in the numerical study.

\subsubsection{The influence of inclusion characteristics on stress distribution in a single-inclusion system}

A single-inclusion model, with all other properties being the same as explained for the model shown in Figure 9, is adopted here to elucidate the effect of softer and harder inclusions (relative to the stiffness of the matrix) on the overall Von Mises stress distribution in the composite. Under uniaxial loading conditions, the intensities of second and third principal stresses are observed to be much lower than the first eigenvalue. Thus, von Mises stress can be considered to be a good representation of the first principal stress, which can be related to compressive strength for brittle materials. A uniform pressure of $40 \mathrm{MPa}$ is applied on the top face of the microstructure that contains a quartz particle (Figure 10(a)) or a PCM particle (Figure 10(b)). A general observation of the stress distribution in Figure 10(a) suggests that the stress is mainly concentrated inside the quartz particles that have significantly higher strength and stiffness than the surrounding paste. This relieves the compressive stress in the paste. The stresses in the quartz-paste interface also increase in the process and the interfacial zone becomes critical in terms of failure since it is weaker than the bulk paste. On the other hand, when a PCM particle is introduced into the paste, the softer (than paste) PCM particle experiences negligible stresses (Figure 10(b)), and the stress is concentrated at the PCM-paste interface. Similar observations are reported for soft particles elsewhere [60]. Note that the PCM shell is very strong ( 250 MPa) and the interface between paste and PCM-E is assumed to be slightly stronger than the bulk paste (see the following section). Consequently, the paste phase experiences increased stresses as the PCM is only marginally involved in load sharing. A comparison of these figures also indicates that a zone directly above and below the quartz particle is highly stressed, whereas the corresponding stress is much lower in the PCM inclusion case. Thus it is likely that the failure patterns would be different in both these cases. There is also a need to consider like and unlike particle interactions which is shown in the following section. 

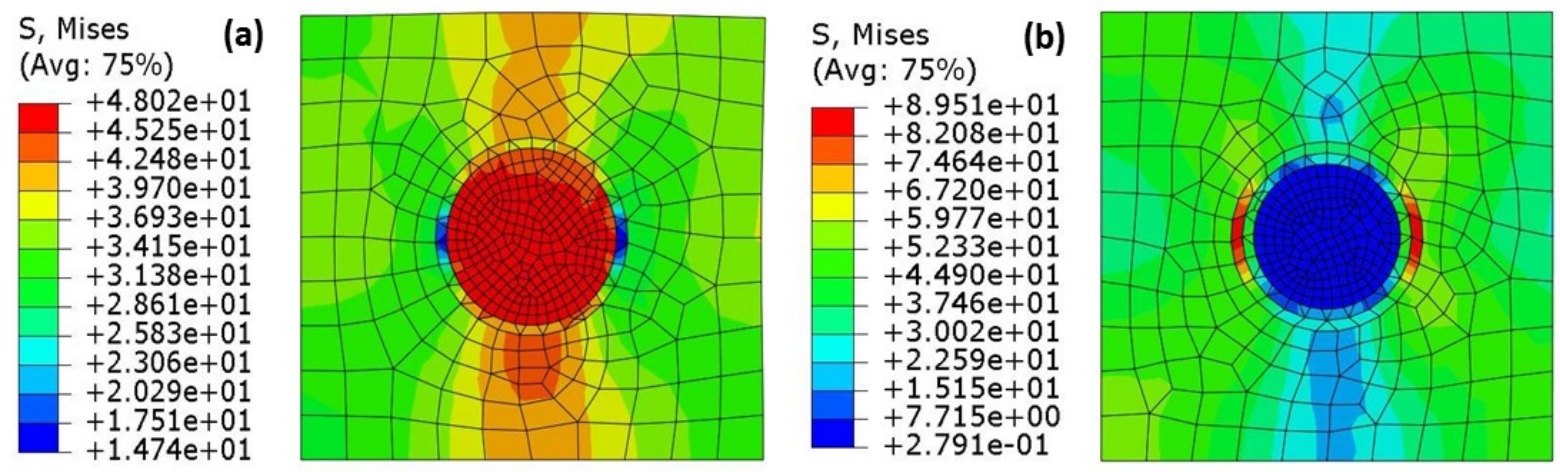

Figure 10: The influence of: (a) hard (quartz) particle, and (b) soft (PCM-E) particle on the stress distribution in the composite. The color schemes in both the figures are dissimilar and hence do not represent the same stress level. Refer to the individual stress levels listed. von Mises stresses (in MPa) indicated in these figures have been used to study the compressive response of particulate composite systems $[61,62]$.

\subsubsection{Stress distributions and probable failure patterns in multiple-inclusion systems}

The model shown in Figure 9 is implemented to understand the influence of inter-inclusion interactions and the volume fraction of PCM-E on the stress distributions and probable failure patterns of the mortars. This paper does not explicitly consider failure theories and thus the probability of failure is judged by a simple strength-of-materials approach., i.e., when the stress exceeds the element strength in compression. A uniform pressure of $40 \mathrm{MPa}$ is applied on the top face. Figures 11 (a), (c), and (e) represent the stress distribution in plain mortar with $50 \%$ quartz inclusion by volume, mortar with 10\% replacement of quartz sand by PCM, and mortar with $50 \%$ replacement of quartz by PCM respectively.

In the plain mortar with $50 \%$ quartz inclusions (Figure 11(a)), the stresses are concentrated inside the quartz inclusions and at the paste-quartz interface as seen previously in the single-inclusion model. Since all the inclusions are of the same nature, a single-inclusion model is capable of adequately capturing this behavior. Note that the stresses in the microstructure are very similar for the singleinclusion (Figure 10(a)) and multiple-inclusion cases (Figure 11(a)).

When $10 \%$ of quartz is replaced by the softer (than paste) PCM with a strong shell, stress concentrations appear in the PCM-paste interface as shown in Figure 11(c), but the stress levels (peak stress and range) are reduced as compared to the single-inclusion model shown in Figure 10(b). This is because the stress is transferred partially to the quartz inclusions (note the increase in concentrated stress in the quartz particle farther from the PCMs as compared to that in single inclusion model). The quartz particles are much stronger and this stress level is unlikely cause their failure. Thus, inter-inclusion interactions becomes important in dictating failure. Also note that the quartz particles that are the nearest neighbors 
to the PCMs have lower stresses than those away from the PCM, because the stresses are transferred to the matrix in the vicinity of the PCM particles. Even then, the maximum stress in the paste away from any of the interfaces is only about $10 \%$ higher than that of the case when no PCMs are present. These observations reinforce two important aspects from a strength viewpoint that need to be considered when particles similar to PCM-E are used in small volumes in cementitious systems - the need to: (i) strengthen the cement paste (matrix) phase, and (ii) use stronger aggregates (both fine and coarse). Figure $11(\mathrm{e})$ shows the stress distribution when $50 \%$ of quartz is replaced by the softer PCM particles. Notice the significant increase in paste stresses, which is more than double than that of the case in which no PCMs are present. In other words, the paste is likely to fail at a much lower load as compared to the previous two cases, when higher volume fractions of PCMs are used.

In an attempt to discern the zones of probable failure in these three model systems, the stresses in Figures 11(a), (c), and (e) are grouped into four ranges: (i) $\sigma<40 \mathrm{MPa}$, (ii) $40 \mathrm{MPa} \leq \sigma \leq 50 \mathrm{MPa}$, (iii) 50 $\mathrm{MPa} \leq \sigma \leq 60 \mathrm{MPa}$, and (iv) $\sigma>60 \mathrm{MPa}$. This considers the compressive strength of the cement paste to be $50 \mathrm{MPa}$, and that of the quartz-paste and PCM-paste interfaces to be $40 \mathrm{MPa}$ and $60 \mathrm{MPa}$ respectively. It must be mentioned that the chosen values of the interfacial strengths serve a vivid representation of the failure zones; even if only smaller differences are maintained between the paste and the interfacial strengths, the same behavior will be noticed. Figures $11(b)$, (d), and (f) depicts the failure regions in these systems.

For the plain mortar without any PCM inclusions, Figure 11(b) shows that the quartz-paste interface stresses are greater than its strength which is taken as $40 \mathrm{MPa}$. The likely failure of the interface results in the stresses being transferred to the nearby interfacial elements and thus the most probable failure path in this system progresses around the inclusions. Similar observations on failure of cement mortars have been reported elsewhere [63]. For the mortar where $\sim 10 \%$ of quartz is replaced with PCM-E, there are localized and discontinuous stress concentrations at the PCM-paste interface, which results in the stresses being released in the neighboring quartz-matrix interfaces as well as quartz particles in the direction of applied pressure (Figure 11(d)). Since the PCM-paste interface is expected to be stronger than the bulk paste, the failure path will still be concentrated along the quartz-paste interfacial elements as shown in Figure 11(d). However, the probability of failure is reduced as compared to the pure quartz system because of reduced number of quartz-paste interfacial elements that have stress concentrations that exceed the failure stress, which is evident when Figures $11(b)$ and $11(d)$ are compared. This is 
reflected in the form of improved strength when low volumes of PCM-E are used as sand replacement in mortars, as shown in Figure 8.
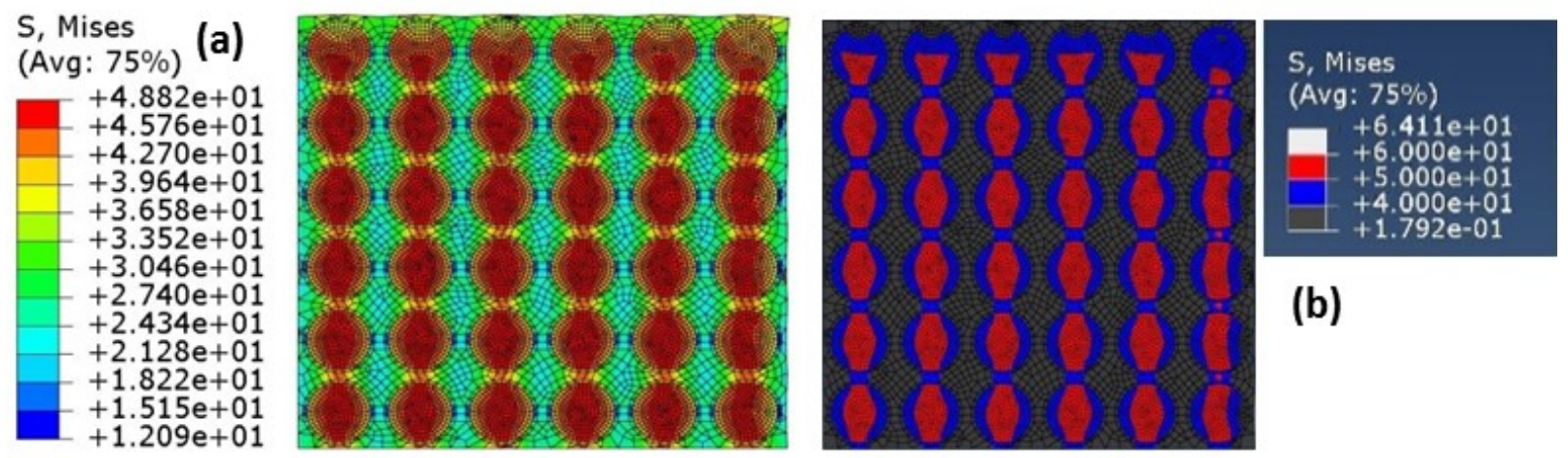

(b)
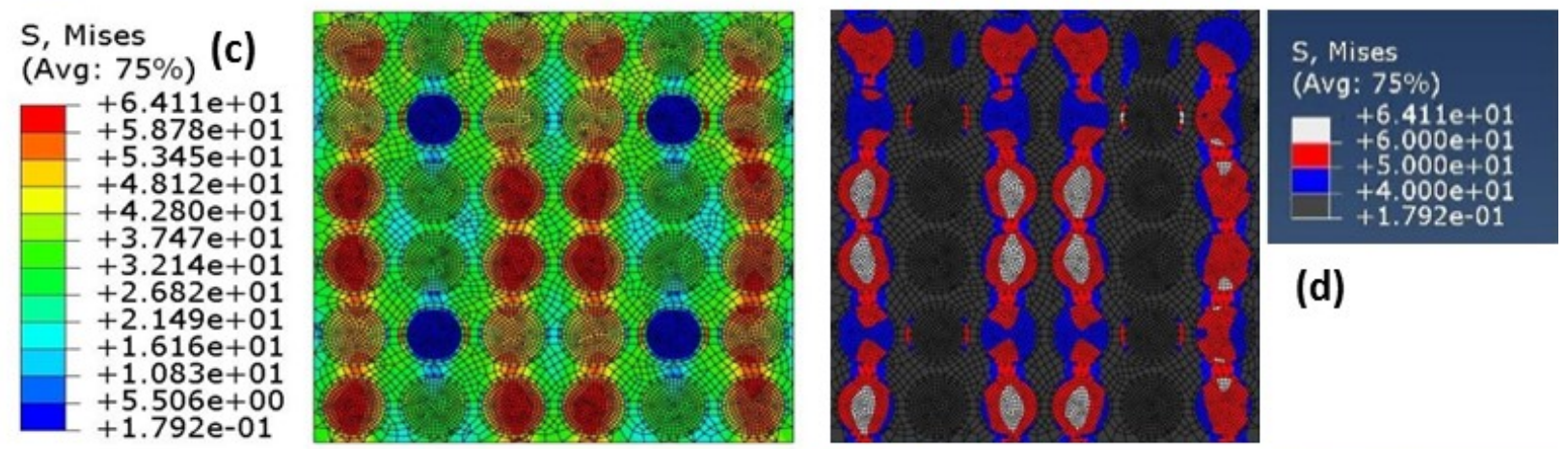

(d)
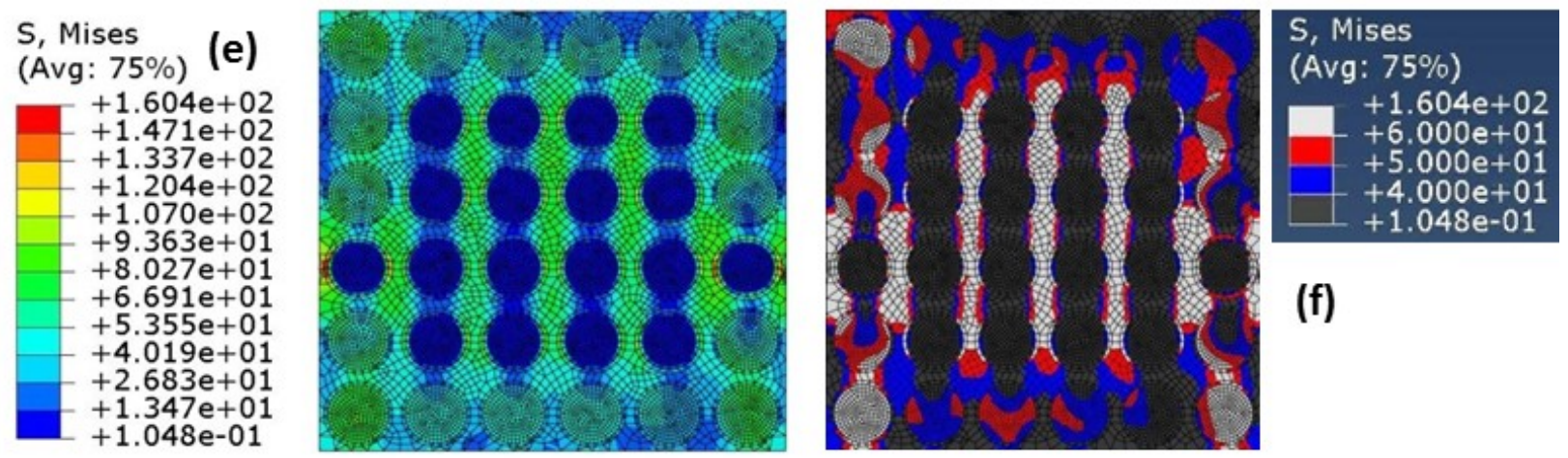

(f)

Figure 11: von Mises Stress (MPa) distributions $(a, c, e)$ in the mortars and a representation of the probable failure patterns (b, d, f): (a) and (b) plain mortar with $50 \%$ quartz inclusions; (c) and (d) mortar with $10 \%$ PCM-E replacing quartz; (e) and (f) mortar with 50\% PCM-E replacing quartz. Note that the color schemes are different for figures (a), (c), and (e).

It is also worthwhile to extrapolate the results to account for the effects of PCM/quartz sizes and dispersion in realistic systems. Replacing a small volume of quartz by PCM-E results in more particles of PCM-E than the quartz that it replaces. Thus the already existing areas of stress concentrations around 
the PCMs shown in Figure 11(d) will be dispersed further, resulting in the stresses in the paste also being more evenly distributed. Moreover, increased number of stronger PCM-paste interfaces and an increase in the tortuosity of the paths connecting the stress concentrations, are likely to lead to an increased load carrying capacity for this system. The simulations presented here have not taken into account the beneficial energy dissipating effect of the softer particles and their contribution towards preventing crack propagation and coalescence.

When a mortar with substantial amount of quartz particles are replaced by PCMs as shown in Figure 11(e), it is very likely that many of the PCM particles will have many other PCM particles as their nearest neighbors. This will lead to the paste matrix between these particles being highly stressed, the stresses being far greater than their failure stress, as is shown in Figure 11(f). Thus, more probable paths of failure propagate through the matrix and the material potentially fails through the paste at a much lower load as compared to plain mortar and the mortar with $10 \%$ PCMs replacing sand. This explains the strength deterioration at higher volume fractions of PCMs. The FE analysis presented here provides an insight into the effect of PCM inclusions on the compressive strength of cement mortars. The analysis, which is conservative by virtue of it not accounting for the implications of inclusion size differences and its dispersion in the paste, is useful towards rational material design of PCM-cement composites by helping tailor the properties of the paste phase, inclusion properties, and the volume fraction of PCMs (within limits) in order to mitigate strength loss in these composite systems.

\subsection{CONCLUSIONS}

This paper has characterized two different microencapsulated PCMs and examined their influence on compressive strength of cementitious composites. The shell material, core-to-shell ratio, and the thermal characteristics (enthalpy and phase change temperature) were different for both the PCMs. The PCMs were also different in morphological characteristics: PCM-M consisted of aggregations ranging between 10 and $300 \mu \mathrm{m}$ which were comprised of smaller nodules less than $5 \mu \mathrm{m}$ in diameter, and PCME consisted of discrete individual particles with a median particle size of $7 \mu \mathrm{m}$. Not surprisingly, the latter particles were found to disperse uniformly when examined using $\mu$-CT while the former showed breakage of capsules into individual smaller nodules. While the pastes containing both the PCMs showed similar total porosities, the critical pore sizes were lower for the pastes containing PCM-E, indicating microstructural refinement.

The mortars where quartz sand was replaced by varying volume fractions demonstrated increase in compressive and flexural strengths until a certain replacement level of PCM-E whereas for mortars 
containing PCM-M, the strengths continually decreased with PCM incorporation. The disintegration of PCM-M resulted in them acting essentially as voids in the matrix. A 2D plane strain finite element model was used to examine the influence of interaction between quartz, PCM-E, and the paste matrix on stress sharing. In the plain mortar with $50 \%$ quartz inclusions, the stresses were concentrated inside the quartz inclusions and at the paste-quartz interface, which was also confirmed by a single-inclusion model. The weaker paste-quartz interfacial elements resulted in the most likely failure path progressing around the inclusions. In systems where small amounts of quartz was replaced by PCM, localized stress concentrations were observed at the PCM-paste interface, but the PCMs being few and far between, the predicted failure region was still along the weaker paste-quartz interface. The probability of failure was reduced in this case as compared to the pure quartz system because of reduced number of quartz-paste interfacial elements. In realistic systems, this effect will be more prominent because of the relative size and dispersion of quartz/PCM inclusions, which will lead to more dispersed PCM-paste interfacial stress concentrations and increased tortuosity of the crack paths. When the system contained a substantial amount of PCMs, the stress concentrations at the paste-PCM interfaces grew, and the likelihood of paste failure increased substantially. The conservative FE analysis presented here could be useful towards tailoring the component phase properties and volume fraction of PCMs to mitigate strength loss.

\subsection{ACKNOWLEDGEMENTS}

The authors acknowledge the financial support from the National Science Foundation (CMMI: 1130028) towards this study. The first author acknowledges a Dean's Fellowship from the Ira A. Fulton Schools of Engineering at Arizona State University (ASU). This research was conducted in the Laboratory for the Science of Sustainable Infrastructural Materials and the 4D Materials Science Laboratory at ASU. The support that has made these laboratories possible are acknowledged. JCEM and NC acknowledge support from the Security and Defense Systems Initiative (SDSI) at ASU. NK acknowledges support from The Scientific and Technological Research Council of Turkey (TUBITAK). The contents of this paper reflect the views of the authors who are responsible for the facts and accuracy of the data presented herein, and do not necessarily reflect the views and policies of the funding agency, nor do the contents constitute a standard, specification, or a regulation.

\subsection{REFERENCES}

[1] Cao L, Su D, Tang Y, Fang G, Tang F. Properties evaluation and applications of thermal energystorage materials in buildings. Renew Sustain Energy Rev 2015;48:500-22. 
[2] Demirbas MF. Thermal energy storage and phase change materials: An overview. Energy Sources Part B 2006;1:85-95.

[3] Kong X, Lu S, Li Y, Huang J, Liu S. Numerical study on the thermal performance of building wall and roof incorporating phase change material panel for passive cooling application. Energy Build 2014;81:404-15.

[4] Khudhair AM, Farid MM. A review on energy conservation in building applications with thermal storage by latent heat using phase change materials. Energy Convers Manag 2004;45:263-75.

[5] Hembade L, Neithalath N., Rajan SD. Understanding the energy implications of phase-change materials in concrete walls through finite-element analysis. ASCE J Energy Eng 2014; 140.

[6] Ling T-C, Poon C-S. Use of phase change materials for thermal energy storage in concrete: An overview. Constr Build Mater 2013;46:55-62.

[7] Cabeza LF, Castell A, Barreneche C, de Gracia A, Fernández Al. Materials used as PCM in thermal energy storage in buildings: A review. Renew Sustain Energy Rev 2011;15:1675-95.

[8] Kuznik F, David D, Johannes K, Roux J-J. A review on phase change materials integrated in building walls. Renew Sustain Energy Rev 2011;15:379-91.

[9] Kuznik F, Johannes K, David D. - Integrating phase change materials (PCMs) in thermal energy storage systems for buildings. In: Cabeza LF, editor. Adv. Therm. Energy Storage Syst., Woodhead Publishing; 2015, p. 325-53.

[10] Memon SA, Cui H, Lo TY, Li Q. Development of structural-functional integrated concrete with macro-encapsulated PCM for thermal energy storage. Appl Energy 2015;150:245-57.

[11] Memon SA. Phase change materials integrated in building walls: A state of the art review. Renew Sustain Energy Rev 2014;31:870-906.

[12] Su W, Darkwa J, Kokogiannakis G. Review of solid-liquid phase change materials and their encapsulation technologies. Renew Sustain Energy Rev 2015;48:373-91.

[13] Tyagi VV, Kaushik SC, Tyagi SK, Akiyama T. Development of phase change materials based microencapsulated technology for buildings: A review. Renew Sustain Energy Rev 2011;15:137391.

[14] Eddhahak-Ouni A, Drissi S, Colin J, Neji J, Care S. Experimental and multi-scale analysis of the thermal properties of Portland cement concretes embedded with microencapsulated Phase Change Materials (PCMs). Appl Therm Eng 2014;64:32-9.

[15] Lecompte T, Le Bideau P, Glouannec P, Nortershauser D, Le Masson S. Mechanical and thermophysical behaviour of concretes and mortars containing phase change material. Energy Build 2015;94:52-60.

[16] Shi X, Memon SA, Tang W, Cui H, Xing F. Experimental assessment of position of macro encapsulated phase change material in concrete walls on indoor temperatures and humidity levels. Energy Build 2014;71:80-7.

[17] Hunger M, Entrop AG, Mandilaras I, Brouwers HJH, Founti M. The behavior of self-compacting concrete containing micro-encapsulated Phase Change Materials. Cem Concr Compos 2009;31:731-43.

[18] Fernandes F, Manari S, Aguayo M, Santos K, Oey T, Wei Z, et al. On the feasibility of using phase change materials (PCMs) to mitigate thermal cracking in cementitious materials. Cem Concr Compos 2014;51:14-26.

[19] Memon SA, Cui HZ, Zhang H, Xing F. Utilization of macro encapsulated phase change materials for the development of thermal energy storage and structural lightweight aggregate concrete. Appl Energy 2015;139:43-55.

[20] Bentz DP, Turpin R. Potential applications of phase change materials in concrete technology. Cem Concr Compos 2007;29:527-32. 
[21] Sharma B. Incorporation of Phase Change Materials into Cementitious Systems. Arizona State University 2014.

[22] Sakulich AR, Bentz DP. Incorporation of phase change materials in cementitious systems via fine lightweight aggregate. Constr Build Mater 2012;35:483-90.

[23] Shilpa M. Thermal response of cementitious systems incorporating phase change materials. Clarkson University, 2011.

[24] Lucas SS, Ferreira VM, de Aguiar JLB. Latent heat storage in PCM containing mortars-Study of microstructural modifications. Energy Build 2013;66:724-31.

[25] Mertens JCE, Williams JJ, Chawla, N.. Note: Design and construction of a multi-scale, highresolution, tube-generated X-Ray computed-tomography system for three-dimensional (3D) imaging. Rev Sci Instrum 2014;85:016103.

[26] Mertens JCE, Williams JJ, Chawla N. Development of a lab-scale, high-resolution, tube-generated Xray computed-tomography system for three-dimensional (3D) materials characterization. Mater Charact 2014;92:36-48.

[27] Mertens JCE, Chawla N. Modeling and characterization of X-ray yield in a polychromatic, lab-scale, X-ray computed tomography system. Nucl Instrum Methods Phys Res Sect Accel Spectrometers Detect Assoc Equip 2015;783:110-6.

[28] Vance KE. Early Age Characterization and Microstructural Features of Sustainable Binder Systems for Concrete. ASU Electron. Diss. Theses, Arizona State University; 2014.

[29] Shi D, Winslow DN. Contact angle and damage during mercury intrusion into cement paste. Cem Concr Res 1985;15:645-54.

[30] Liabastre AA, Orr C. An evaluation of pore structure by mercury penetration. J Colloid Interface Sci 1978;64:1-18.

[31] Borreguero AM, Valverde JL, Rodríguez JF, Barber AH, Cubillo JJ, Carmona M. Synthesis and characterization of microcapsules containing Rubitherm ${ }^{\circledR} \mathrm{RT} 27$ obtained by spray drying. Chem Eng J 2011;166:384-90.

[32] Sánchez L, Sánchez P, Carmona M, Lucas A de, Rodríguez JF. Influence of operation conditions on the microencapsulation of PCMs by means of suspension-like polymerization. Colloid Polym Sci 2008;286:1019-27.

[33] Qiu X, Li W, Song G, Chu X, Tang G. Microencapsulated n-octadecane with different methylmethacrylate-based copolymer shells as phase change materials for thermal energy storage. Energy 2012;46:188-99.

[34] Jyothi NVN, Prasanna PM, Sakarkar SN, Prabha KS, Ramaiah PS, Srawan GY. Microencapsulation techniques, factors influencing encapsulation efficiency. J Microencapsul 2010;27:187-97.

[35] Su J-F, Wang X-Y, Dong $\mathrm{H}$. Micromechanical properties of melamine-formaldehyde microcapsules by nanoindentation: Effect of size and shell thickness. Mater Lett 2012;89:1-4.

[36] Arima T, Murata H, Hamada T. Properties of highly cross-linked autopolymerizing reline acrylic resins. J Prosthet Dent 1995;73:55-9.

[37] Giro-Paloma J, Oncins G, Barreneche C, Martínez M, Fernández Al, Cabeza LF. Physico-chemical and mechanical properties of microencapsulated phase change material. Appl Energy 2013;109:441-8.

[38] Li W, Song G, Tang G, Chu X, Ma S, Liu C. Morphology, structure and thermal stability of microencapsulated phase change material with copolymer shell. Energy 2011;36:785-91.

[39] Ullah S, Bustam MA, Nadeem M, Naz MY, Tan WL, Shariff AM. Synthesis and Thermal Degradation Studies of Melamine Formaldehyde Resins. Sci World J 2014;2014.

[40] Su J-F, Huang Z, Ren L. High compact melamine-formaldehyde microPCMs containing noctadecane fabricated by a two-step coacervation method. Colloid Polym Sci 2007;285:1581-91. 
[41] Su J-F, Wang X-Y, Dong H. Influence of temperature on the deformation behaviors of melamineformaldehyde microcapsules containing phase change material. Mater Lett 2012;84:158-61.

[42] Palanikkumaran M, Gupta KK, Agrawal AK, Jassal M. Highly stable hexamethylolmelamine microcapsules containing n-octadecane prepared by in situ encapsulation. J Appl Polym Sci 2009;114:2997-3002.

[43] Su J-F, Wang X-Y, Dong H. Interface Stability of Microencapsulated-Paraffin Filled Epoxy Composites: Effect of Methylation on Melamine-Formaldehyde Shell Material. Compos Interfaces 2011;18:645-59.

[44] Shan XL, Wang JP, Zhang XX, Wang XC. Formaldehyde-free and thermal resistant microcapsules containing n-octadecane. Thermochim Acta 2009;494:104-9.

[45] Provis JL, Myers RJ, White CE, Rose V, van Deventer JSJ. X-ray microtomography shows pore structure and tortuosity in alkali-activated binders. Cem Concr Res 2012;42:855-64.

[46] Hu C, Li Z. Micromechanical investigation of Portland cement paste. Constr Build Mater 2014;71:44-52.

[47] Deo O, Neithalath N. Compressive behavior of pervious concretes and a quantification of the influence of random pore structure features. Mater Sci Eng A 2010;528:402-12.

[48] Hu J. Porosity in concrete - morphological study of model concrete. Delft University, 2004.

[49] Lutz MP, Monteiro PJM, Zimmerman RW. Inhomogeneous interfacial transition zone model for the bulk modulus of mortar. Cem Concr Res 1997;27:1113-22.

[50] Zhu W, Bartos PJM. Application of depth-sensing microindentation testing to study of interfacial transition zone in reinforced concrete. Cem Concr Res 2000;30:1299-304.

[51] Lee KM, Park JH. A numerical model for elastic modulus of concrete considering interfacial transition zone. Cem Concr Res 2008;38:396-402.

[52] Scrivener KL, Crumbie AK, Laugesen P. The Interfacial Transition Zone (ITZ) Between Cement Paste and Aggregate in Concrete. Interface Sci 2004;12:411-21.

[53] Yang CC. Effect of the Transition Zone on the Elastic Moduli of Mortar. Cem Concr Res 1998;28:727-36.

[54] Constantinides G, Ulm F-J. The effect of two types of C-S-H on the elasticity of cement-based materials: Results from nanoindentation and micromechanical modeling. Cem Concr Res 2004;34:67-80.

[55] Hagstrand PO, Oksman K. Mechanical properties and morphology of flax fiber reinforced melamine-formaldehyde composites. Polym. Compos. 2001; 22:568-578.

[56] Konnerth J, Gindl W, Müller U. Elastic properties of adhesive polymers. I. Polymer films by means of electronic speckle pattern interferometry. J Appl Polym Sci 2007;103:3936-9.

[57] Daphalapurkar NP, Wang F, Fu B, Lu H, Komanduri R. Determination of Mechanical Properties of Sand Grains by Nanoindentation. Exp Mech 2010;51:719-28.

[58] Hussain ME. Experimental study of physical and mechanical properties of natural and synthetic waxes using uniaxial compressive strength test. Proc Third Int Conf Model Simul Appl Optim 2009:20-2.

[59] Mercadé-Prieto R, Allen R, Zhang Z, York D, Preece JA, Goodwin TE. Failure of elastic-plastic coreshell microcapsules under compression. AIChE J 2012;58:2674-81.

[60] Gilabert FA, Garoz D, Van Paepegem W. Stress concentrations and bonding strength in encapsulation-based self-healing materials. Mater Des 2015;67:28-41.

[61] Proulx T. Experimental and Applied Mechanics, Volume 6: Proceedings of the 2011 Annual Conference on Experimental and Applied Mechanics. Springer Science \& Business Media; 2011.

[62] Andreasen JH, Karihaloo BL. Mechanics of Transformation Toughening and Related Topics. Elsevier; 1996. 
[63] Buyukozturk O, Nilson AH. Stress-Strain Response and Fracture of a Concrete Model in Biaxial Loading. ACI J Proc 1971. 